\title{
Clinical Profile of the Patients Undergoing Awake Fiberoptic Intubation Along with Airway Blocks in Cervical Discectomy Patients
}

\author{
Bhaskar Babu BD', Padma S \\ ${ }^{1}$ Associate Professor, Department of Anesthesiology, Sapthagiri Institute of Medical Science and Research center, Bengaluru, Karnataka, ${ }^{2}$ Assistant \\ Professor, Department of Anesthesiology, Sapthagiri Institute of Medical Science and Research center, Bengaluru, Karnataka.
}

\section{Abstract}

Background: The optical characteristics of fine glass strands are what make fiberoptic technology possible. When glass rods are heated and stretched to diameters of 8 to $25 \mu$, a flexible fiber capable of transmitting light is formed. Light that enters the distal end of the fiber is reflected off the walls until it emerges at the proximal end. To keep a fraction of the light from being lost during transmission, the fiber is clad in a layer of glass that has a different optical density. This process results in total internal reflection of light entering the fiber. The light transmitted along a single fiber emerges uniformly distributed over the cross-sectional area at the end. The resolution of a fiberoptic image is inversely proportional to the diameter of the glass fiber. Subjects and Methods: After overnight fasting, all patients under the study were premedicated with tab ranitidine $150 \mathrm{mg}$ orally and tab diazepam $10 \mathrm{mg}$ with sips of water 90 mins before shifting to operating theatre. Premedication with glycopyrrolate $0.2 \mathrm{mg} \mathrm{IM}$, administered 30-45 minutes prior to application of the local anesthetic. Results: At baseline, SO2 in both the groups were comparable. There were no significant differences between the groups with respect to changes in $\mathrm{SO} 2$ after bolus infusion, during intubation and after intubation clinically. Conclusion: Patients with study (D) group had a consciousness score of 2 (eyes open on command) in 41 patients out of $50(82 \%)$, where as in control (P) group 17 patients $(34 \%)$ had score of 2 (eyes open on command). 20 patients (40\%) had score of 1 (response to ear pinching), in control (P) group compared to 3 patients in study(D) group.

Keywords: Clinical Profile, Awake fiberoptic intubation, Cervical discectomy.

Corresponding Author: Dr. Padma S, Assistant Professor, Department of Anesthesiology, Sapthagiri Institute of Medical Science and Research center, Bengaluru, Karnataka.

Received: June 2019

Accepted: June 2019

\section{Introduction}

The use of fiberoptic scopes to assist in endotracheal intubation dates back to 1967 , when a choledocoscope was used to intubate a patient with Still's disease. The first case series of the use of fiberscopes for intubation was published in 1972. Their use in anesthesia greatly expanded after the publication of the ASA Guidelines on Difficult Airway Management. Current uses include nasal and oral intubations (either in the awake or anesthetized patient), evaluation of the airway, verification of accurate placement of single-or double-lumen endotracheal tubes and laryngeal mask airways (LMA), endotracheal tube exchange, and placement of bronchial blocker devices. ${ }^{[1]}$

The optical characteristics of fine glass strands are what make fiberoptic technology possible. When glass rods are heated and stretched to diameters of 8 to $25 \mu$, a flexible fiber capable of transmitting light is formed. Light that enters the distal end of the fiber is reflected off the walls until it emerges at the proximal end. To keep a fraction of the light from being lost during transmission, the fiber is clad in a layer of glass that has a different optical density. This process results in total internal reflection of light entering the fiber. The light transmitted along a single fiber emerges uniformly distributed over the cross-sectional area at the end. The resolution of a fiberoptic image is inversely proportional to the diameter of the glass fiber. To generate an actual image of an object, approximately 10,000 individual fibers are bound into a bundle, which can result in the microscopic equivalent of a cubist painting unless each individual fiber is in the exact same orientation at one end of the fiber as at the other (a coherent bundle). This is akin to the way one's retina or the individual pixels on a computer screen forms an image. The FOB contains another set of fiberoptic bundles that transmit light to the end of the insertion cord for illumination. These fiberoptic bundles do not need to be arranged in a coherent fashion.

Fiberoptic endoscopes used for intubation come in contact with mucosal surfaces and are considered semi-critical devices by the E.H. Spaulding Classification of Patient Care Items, which require a minimum of high-level disinfection between uses. As soon as possible after using the FOB, all surfaces should undergo cleaning with a low-sudsing enzymatic detergent followed by rinsing to remove organic material. The channel should be irrigated with the detergent solution and a specially designed brush used to remove particulate matter. Disposable brushes should be used or they 
0

also should undergo high-level disinfection. ${ }^{[2]}$

The FOB should be tested for leaks. A scope that does not pass the leakage test should not undergo the next steps in the cleaning process but should be sent for repair. After successful leak testing, the scope is either liquid or gas sterilized. The disinfecting agent must be in contact with all surfaces of the FOB for the recommended period of time.

The Environmental Protection Agency-recommended agents for high-level disinfection include $2 \%$ alkaline or acid glutaraldehyde, $6 \%$ hydrogen peroxide/ $0.85 \%$ phosphoric acid, and $1 \%$ peracetic acid.

The FOB is most commonly processed by a Steris System (Steris Corporation, Mentor, $\mathrm{OH}$ ) (peracetic acid) or ethylene oxide gas sterilization. After liquid processing, the external surfaces and channel of the scope should be rinsed with water. The channel then should have air aspirated through it for 60 seconds if sterile water was used for rinsing. If nonsterile water was used, the channel should have $70 \%$ alcohol suctioned through it. The scope is then allowed to dry.

Each manufacturer of FOBs has specific recommendations for the processing of their scopes. The recommendations even may be specific for different scopes made by the same manufacturer. The recommendations should be followed so that the scope does not sustain damage or the warranty became voided. ${ }^{[3]}$

The Pressor response to laryngoscopy and endotracheal intubation has been recognized since 1951. It is a sympathetic reflex provoked by stimulation of the epipharynx and laryngo-pharynx. The increase in the blood pressure and pulse rate are transitory. They may especially be hazardous to patients with hypertension, myocardial insufficiency or coronary vascular disease, traumatic injury to the brain or the eye, cerebrovascular disease. ${ }^{[4]}$

The pressor response is a reflex in nature. It is evident from the fact that it appears immediately as stimulus is applied. The work of Tomori and Widdicombe has shown that it results in the activation of the sympatho-adrenal system. The major influences on the cardiovascular regulation are mediated through the autonomous nervous system and the hormonal system. ${ }^{[5]}$

\section{Subjects and Methods}

\section{Inclusion Criteria:}

- Age: $20-60$ years.

- ASA grade: I / II.

- Cervical disc patients.

- Elective surgery

\section{Exclusion Criteria:}

- Clinically significant neurologic, cardiovascular, renal, hepatic, or gastrointestinal diseases

- Heart block > first degree or heart rate $<50$ beats / minute

- A history of alcohol or drug abuse (e.g. Opioids )

- Known allergy, sensitivity, asthma, contraindications to any study drug.

- Current h/o psychiatric disorder or presently on psychotropic medications

- Pregnancy
Written consent from the patients involved in the study was taken. Patients were randomly distributed into two groups using computer generated random table.

Study Group - D (Dexmedetomidine): Fifty patients received intravenous dexmedetomidine. Dexmedetomidine was given as loading dose of $1 \mathrm{mcg} / \mathrm{kg}$ over 10 minutes and maintenance dose of $0.5 \mathrm{mcg} / \mathrm{kg}$ until the endotracheal was secured.

Control Group - P (Propofol): Fifty Patients received intravenous propofol. Propofol was given undiluted as a bolus dose of $1 \mathrm{mg} / \mathrm{kg}$ over $5 \mathrm{mins}$ followed by $0.5 \mathrm{mg} / \mathrm{kg}$ until tube was secured.

After overnight fasting, all patients under the study were premedicated with tab ranitidine $150 \mathrm{mg}$ orally and tab diazepam $10 \mathrm{mg}$ with sips of water 90 mins before shifting to operating theatre. Premedication with glycopyrrolate $0.2 \mathrm{mg}$ IM, administered 30-45 minutes prior to application of the local anesthetic.

Preoperative pulse rate, blood pressure, electrocardiogram, non invasive blood pressur, respiratory rate and oxygen saturation were recorded in the operation theatre after connecting to standard anesthesia monitor [Comprehensive monitoring system, Agilent technologies, Andover, USA]. Peripheral venous access and arterial line were established after local infiltration of lignocaine. Oxygen was administered to the patient by nasal cannula, the study and control medications were administered as intravenous infusion and patients were assessed constantly to ensure they respond to verbal commands.

Topical Anesthesia of the Mouth and Oropharynx was carried out using $5 \mathrm{ml}$ of $2 \%$ viscous lidocaine gargle (swish and swallow) for 5 mins.

Superior Laryngeal Nerve block was carried out. The cornu of the hyoid bone was palpated transversally with the thumb and the index finger on the side of the neck immediately beneath the angle of the mandible and anterior to the carotid artery. To facilitate its identification, the hyoid bone was displaced toward the side being blocked. One hand displaces the carotid artery laterally and posteriorly. With the other hand, a 22 guage hypodermic needle was "walked off" the cornu of the hyoid bone in an anterior caudad direction, aiming in the direction of the thyroid ligament, until it was passed through the ligament. At a depth of 1-2 cm, $2 \mathrm{ml}$ of $2 \%$ lidocaine without adrenaline was injected (after negative air and blood aspiration) into the space between the thyrohyoid membrane and the pharyngeal mucosa, needle was withdrawn and the block was repeated on the other side. Recurrent Laryngeal Nerve Block /Transtracheal or Translaryngeal Block was carried out. Index and third fingers of the non-dominant hand was placed in the space between the thyroid and cricoid cartilages identifying the cricothyroid membrane. The trachea was held in place by placing the thumb and third finger on either side of the thyroid cartilage. The midline was then identified and injected lightly to create a local skin wheal using a 22-guage hypodermic needle.

A $10 \mathrm{ml}$ syringe containing $4 \mathrm{ml}$ of $2 \%$ lidocaine without adrenaline was mounted on a 22 -guage venous cannula, and was introduced into the trachea. The catheter was advanced into the lumen, midline through the cricothyroid membrane, at an angle of 45 degrees, in a caudal direction. Immediately after the introduction of the catheter into the trachea, a loss 
of airway resistance and aspiration of air confirmed placement, and the needle was removed from the catheter. The patient was then asked to take a deep breath and then asked to exhale forcefully. At the end of the expiratory effort, $4 \mathrm{ml}$ of $2 \%$ lidocaine was rapidly injected into and over the back of the trachea.

Bite block was then lubricated with lidocaine jelly and gently placed in the patient's mouth. . The chin lift and jaw thrust maneuvers, and protrusion of the tongue, moved the soft tissues and improved the view through the fiberscope. These maneuvers also helped to prevent airway obstruction in the sedated patient.

Fiberoptic intubation was carried out by the Senior Anaesthesiologist experienced in this technique.

Insertion cord of FOB loaded with flexometallic tube (size $7.5-8.0 \mathrm{~mm}$ ID for male patients, 7 - $7.5 \mathrm{~mm}$ ID for female patients) was advanced gently through the airway under epiglottis through the cords into the trachea, the tube was gently railroaded into the mid tracheal position .Position of the tube was confirmed as the fiberscope was withdrawn and reconfirmed by bag movement and capnography.

Data was collected using a data collection form. Study parameters like Heart rate, systolic pressure, diastolic pressure, mean arterial pressure, respiratory rate and oxygen saturation were recorded at baseline, 5 mins after bolus infusion, at $30 \mathrm{secs}, 60 \mathrm{secs}, 90 \mathrm{secs}, 120 \mathrm{secs}, 150 \mathrm{secs}, 180$ secs, at 4 th and 5 th mins.

\section{Results}

This study was carried out on a total number of 100 patients. In the present study, intravenous dexmedetomidine (study group) is compared with propofol based sedation (control group) for awake fiberoptic intubation along with airway blocks in cervical discectomy patients.

The mean age in dexmedetomidine (study group) was $42.92 \pm 9.26$ years, with a range of 20 to 60 years. The mean age in propofol (control group) was $42.06 \pm 9.72$ years, with a range of 21 to 60 years. There was no statistically significant difference in the age between the two groups $(\mathrm{P}=0.652)$.

\section{Table 1: Age distribution of patients studied}

\begin{tabular}{|l|l|l|l|l|}
\hline Age in years & \multicolumn{3}{|l|}{ Study group } & \multicolumn{1}{l|}{ Control group } \\
\hline & No & \% & No & \% \\
\hline $20-30$ & 6 & 12.0 & 8 & 16.0 \\
\hline $31-40$ & 14 & 28.0 & 14 & 28.0 \\
\hline $41-50$ & 20 & 40.0 & 18 & 36.0 \\
\hline $51-60$ & 10 & 20.0 & 10 & 20.0 \\
\hline Total & 50 & 100.0 & 50 & 100.0 \\
\hline Mean \pm SD & $42.92 \pm 9.26$ & $42.06 \pm 9.72$ \\
\hline
\end{tabular}

Samples are age matched with $\mathrm{P}=0.652$

Out of the 50 patients in dexmedetomidine group 44 were males and 6 were females, whereas in propofol group 45 were males and 5 were females. There was no statistically significant difference between the two groups in sex distribution $(\mathrm{P}=0.749)$

Table 2: Gender distribution of patients studied.

\begin{tabular}{|c|c|c|c|c|}
\hline \multirow{2}{*}{ Gender } & \multicolumn{2}{|c|}{ Study group } & Control group \\
\cline { 2 - 5 } & No & $\%$ & No & $\%$ \\
\hline Male & 44 & 88.0 & 45 & 90.0 \\
\hline
\end{tabular}

\begin{tabular}{|c|c|c|c|c|}
\hline Female & 6 & 12.0 & 5 & 10.0 \\
\hline Total & 50 & 100.0 & 50 & 100.0 \\
\hline
\end{tabular}

The mean height in dexmedetomidine group (study group) was $159.60 \pm 6.52(138-170) \mathrm{cms}$, and in the propofol group (control group) was $162.04 \pm 6.15(150-178) \mathrm{cms}$. There was no statistically significant difference between the two groups in height distribution $(\mathrm{P}=0.100)$

Table 3: Distribution of Height $(\mathrm{cm})$ in two groups of patients studied

\begin{tabular}{|l|l|l|l|l|}
\hline \multirow{2}{*}{ Height (cm) } & \multicolumn{2}{|l|}{ Study group } & \multicolumn{2}{l|}{ Control group } \\
\cline { 2 - 5 } & No & \% & No & \% \\
\hline$<140$ & 1 & 2.0 & 0 & 0.0 \\
\hline $141-150$ & 4 & 8.0 & 2 & 4.0 \\
\hline $151-160$ & 25 & 50.0 & 20 & 40.0 \\
\hline $161-170$ & 20 & 40.0 & 22 & 44.0 \\
\hline $171-180$ & 0 & 0.0 & 6 & 12.0 \\
\hline Total & 50 & 100.0 & 50 & 100.0 \\
\hline Mean \pm SD & $159.60 \pm 6.52$ & $162.04 \pm 6.15$ & \\
\hline
\end{tabular}

Mean height is statistically similar in two groups with $\mathrm{P}=0.100$

The mean weight in dexmedetomidine (study group) was $58.90 \pm 10.10(42-82) \mathrm{kg}$, and in the propofol (control group) was $57.50 \pm 9.73(40-85) \mathrm{kg}$. There was no statistically significant difference between the two groups in weight distribution $(\mathrm{P}=0.482)$

Table 4: Distribution of Weight (kg) in two groups of patients studied

\begin{tabular}{|l|l|l|l|l|}
\hline \multirow{2}{*}{ Weight $(\mathbf{k g})$} & \multicolumn{2}{|l|}{ Study group } & Control group \\
\cline { 2 - 5 } & No & $\mathbf{\%}$ & No & \% \\
\hline$\leq 40$ & 1 & 2.0 & 2 & 4.0 \\
\hline $41-50$ & 7 & 14.0 & 10 & 20.0 \\
\hline $51-60$ & 26 & 52.0 & 22 & 44.0 \\
\hline $61-70$ & 8 & 16.0 & 11 & 22.0 \\
\hline $71-80$ & 7 & 14.0 & 4 & 8.0 \\
\hline$>80$ & 1 & 2.0 & 1 & 2.0 \\
\hline Total & 50 & 100.0 & 50 & 100.0 \\
\hline Mean \pm SD & \multicolumn{5}{|l|}{} \\
\hline
\end{tabular}

Mean weight is statistically similar in two groups with $\mathrm{P}=0.482$

At baseline, RR in both the groups were comparable. There were significant differences between the groups with respect to changes in RR. There is statically highly significant ( $p$ $<0.001 * *)$ increase in RR after 5 minutes of Bolus infusion $(16.84 \pm 1.33$ vs. $12.34 \pm 1.33)$, during intubation $(17.94 \pm 1.78$ vs. $13.20 \pm 1.21$ ) and upto 5 minutes after intubation with study group. Apnea was observed in few patients who required frequent awakening (10 seconds) in control group.

Table 5: Comparison of RESPIRATORY RATE in two groups of patients studied

\begin{tabular}{|l|l|l|l|}
\hline Respiratory Rate & $\begin{array}{l}\text { Study } \\
\text { group }\end{array}$ & Control group & P value \\
\hline Baseline & $13.08 \pm 0.99$ & $12.78 \pm 1.18$ & 0.172 \\
\hline $\begin{array}{l}5 \text { min after Bolus } \\
\text { Infusion }\end{array}$ & $16.84 \pm 1.33$ & $12.34 \pm 1.33$ & $<0.001^{* *}$ \\
\hline During Intubation & $17.94 \pm 1.78$ & $13.20 \pm 1.21$ & $<0.001^{* *}$ \\
\hline At $30 \mathrm{sec}$ & $17.88 \pm 1.91$ & $12.73 \pm 2.05$ & $<0.001^{* *}$ \\
\hline At $60 \mathrm{sec}$ & $17.88 \pm 2.08$ & $12.16 \pm 2.02$ & $<0.001^{* *}$ \\
\hline At $90 \mathrm{sec}$ & $18.12 \pm 2.11$ & $12.29 \pm 1.95$ & $<0.001^{* *}$ \\
\hline At $120 \mathrm{sec}$ & $18.22 \pm 2.30$ & $12.27 \pm 1.58$ & $<0.001^{* *}$ \\
\hline At $150 \mathrm{sec}$ & $18.02 \pm 2.18$ & $12.45 \pm 1.73$ & $<0.001^{* *}$ \\
\hline At $180 \mathrm{sec}$ & $17.70 \pm 1.98$ & $12.49 \pm 1.95$ & $<0.001^{* *}$ \\
\hline
\end{tabular}




\begin{tabular}{|l|l|l|l|}
\hline 0 & $17.66 \pm 1.77$ & $12.20 \pm 1.78$ & $<0.001^{* *}$ \\
\hline At 4 mins & $17.54 \pm 1.67$ & $12.27 \pm 1.50$ & $<0.001^{* *}$ \\
\hline At 5 mins &
\end{tabular}

At baseline, SO2 in both the groups were comparable. There were no significant differences between the groups with respect to changes in $\mathrm{SO} 2$ after bolus infusion, during intubation and after intubation clinically.

Table 6: Comparison of OXYGEN SATURATION in two
groups of patients studied
\begin{tabular}{|l|l|l|l|}
\hline $\begin{array}{l}\text { Oxygen } \\
\text { Saturation }\end{array}$ & Study group & Control group & P value \\
\hline Baseline & $99.98 \pm 0.14$ & $99.92 \pm 0.34$ & 0.253 \\
\hline $\begin{array}{l}5 \text { min after } \\
\text { Bolus Infusion }\end{array}$ & $99.98 \pm 0.14$ & $99.82 \pm 0.48$ & 0.427 \\
\hline $\begin{array}{l}\text { During } \\
\text { Intubation }\end{array}$ & $99.98 \pm 0.14$ & $99.86 \pm 0.41$ & 0.407 \\
\hline At 30 sec & $100.00 \pm 0.00$ & $99.92 \pm 0.28$ & 0.300 \\
\hline At 60 sec & $100.00 \pm 0.00$ & $99.92 \pm 0.28$ & 0.300 \\
\hline At 90 sec & $100.00 \pm 0.00$ & $99.94 \pm 0.24$ & 0.456 \\
\hline At 120 sec & $100.00 \pm 0.00$ & $99.94 \pm 0.24$ & 0.456 \\
\hline At 150 sec & $100.00 \pm 0.00$ & $99.96 \pm 0.29$ & 0.315 \\
\hline At 180 sec & $99.98 \pm 0.14$ & $99.92 \pm 0.28$ & 0.615 \\
\hline At 4 mins & $100.00 \pm 0.00$ & $99.94 \pm 0.24$ & 0.456 \\
\hline At 5 mins & $100.00 \pm 0.00$ & $99.98 \pm 0.14$ & 0.315 \\
\hline
\end{tabular}

Table 7: Comparison of Patient Sedation Score in two groups of patients studied

\begin{tabular}{|l|l|l|l|}
\hline Patient Sedation Score & $\begin{array}{l}\text { Study } \\
\text { group }\end{array}$ & $\begin{array}{l}\text { Control } \\
\text { group }\end{array}$ & P value \\
\hline Consciousness(0-4) & $2.08 \pm 0.49$ & $1.94 \pm 0.96$ & 0.359 \\
\hline Airway(0-3) & $2.56 \pm 0.61$ & $1.84 \pm 1.02$ & $<0.001^{* *}$ \\
\hline Activity(0-2) & $1.80 \pm 0.49$ & $1.38 \pm 0.73$ & $0.001^{* *}$ \\
\hline Discomfort Score( 0-3) & $0.30 \pm 0.46$ & $0.60 \pm 0.73$ & $0.016^{*}$ \\
\hline Endoscopy Score(0-5) & $1.22 \pm 1.42$ & $2.03 \pm 1.68$ & $0.011^{*}$ \\
\hline Intubation Score (0-5) & $1.89 \pm 1.48$ & $2.79 \pm 1.44$ & $0.003^{* *}$ \\
\hline $\begin{array}{l}\text { Post Intubation } \\
\text { Condition(1-3) }\end{array}$ & $1.00 \pm 0.00$ & $1.02 \pm 0.25$ & 1.000 \\
\hline
\end{tabular}

Patients with study (D) group had a consciousness score of 2 (eyes open on command) in 41 patients out of 50 (82\%), where as in control (P) group 17 patients $(34 \%)$ had score of 2 (eyes open on command). 20 patients (40\%) had score of 1 (response to ear pinching),in control $(\mathrm{P})$ group compared to 3 patients in study(D) group. Thus there was significantly increased percentage of patients with score 2 in study group. ( $82 \%$ vs. $34 \%$ ) where patients were lightly asleep and were easily arousable, responding to commands and they were calm and co-operative. Better conscious score 2(1-3) was more associated with Study group compared to control group 1(1-3).

\section{Discussion}

Peiris K, Frerk C, et al did a study on awake intubation and described that Awake intubation can be achieved via several methods. Using the Fiberoptic laryngoscope is the most widely used technique in the UK with minimal patient discomfort and a wide margin of safety. They concluded that compared with attempts at difficult direct laryngoscopy, awake Fiberoptic intubation provides excellent cardiovascular stability when performed under good topical anaesthesia and conscious sedation. Understanding the equipment used as well as preparing the patient and being aware of potential pitfalls are important elements to performing a successful awake intubation. ${ }^{[6]}$

Andruszkiewicz et al studied on Awake Fiberoptic intubation. They described that Awake Fiberoptic intubation has been recommended for adult patients with a difficult airway in whom anaesthesia and/or relaxation could lead to the "cannot ventilate, cannot intubate" situation, the strategy and protocols of such management in cases with a predicted difficult airway .Concluded that Awake intubation is rarely associated with serious episodes of desaturation and it is usually well tolerated by motivated patients. ${ }^{[7]}$

Takahashi H, Suzuki T, et al they did a study on Anesthesia induction for patients with cervical spinal disease. They performed an Awake induction using AirWay Scope for 8 patients with cervical spinal diseases using Midazolam, propofol or dexmedetomidine as a sedative drug. Intubation was performed easily and safely without any complications in all cases and no patients had memories of intubation. They concluded that Awake intubation using AirWay Scope for patients with cervical spinal diseases is a safe and useful anesthesia method. As dexmedetomidine causes no respiratory depression and can expect cooperation from patients, it may give safe and efficient sedation in awake intubation cases. ${ }^{[8]}$

Crosby ET did a study on Airway management in adults after cervical spine trauma. . All airway interventions cause spinal movement; immobilization may have a modest effect in limiting spinal movement during airway maneuvers. They concluded that many anesthesiologists state a preference for the Fiberoptic bronchoscope to facilitate airway management, although there is considerable, favorable experience with the direct laryngoscope in cervical spinal injury patients. ${ }^{[9]}$

Akhlagh SH, Vaziri MT, Masoumi T, Anbardan SJ. did a trial on eighty patients, forty in ILMA group and forty in DL group, they studied Hemodynamic response to tracheal intubation via direct laryngoscopy and intubating laryngeal mask airway (ILMA) in patients undergoing coronary artery bypass graft (CABG). A significant increase in heart rate and blood pressure was detected in both groups after intubation. Despite existence of noted changes in both groups; quantity of these changes was similar in both groups, however quality of changes was not completely similar. They concluded that ILMA does not have much greater benefit over conventional DL in patients undergoing coronary artery by-pass grafting. ${ }^{[10]}$

Shibata Y, Okamoto K et al did a study and compared the cardiovascular responses between nasal and oral intubation with a Fiberoptic bronchoscope under the combination of neuroleptic analgesia (NLA) and topical anesthesia. The 16 patients studied were divided into 2 groups: the nasal intubation group ( $\mathrm{N}$ group: 8 patients) and the oral intubation group ( $\mathrm{O}$ group: 8 patients). There were significant changes in systolic, diastolic and mean arterial pressures in the $\mathrm{N}$ group and in the pressure rate quotient in the $\mathrm{O}$ group. Diastolic arterial pressure and heart rate were significantly higher in the $\mathrm{N}$ group than in the $\mathrm{O}$ group before induction of general anesthesia. The rate pressure product (RPP) was significantly higher in the $\mathrm{N}$ group than in the $\mathrm{O}$ group at some points during the procedure. The individual RPP in both groups was relatively stable except for one patient in the 
0

$\mathrm{N}$ group, who had a marked increase in RPP during the procedure. They concluded that, under the combination of NLA and topical anesthesia, the cardiovascular responses to oral Fiberoptic intubation are less severe than those to the nasal approach. The oral approach is recommended, especially in patients with coronary artery disease, taking into consideration of the cardiovascular responses to Fiberoptic intubation. ${ }^{[11]}$

Avitsian R, Lin J,et al presented a clinical case series of patients who underwent an awake fiberoptic endotracheal intubation (AFOBI) using dexmedetomidine for sedation, adequate sedation in addition to topicalization of the airway may be key to minimize patient discomfort and assist in successful intubation, These were patients in whom AFOBI was indicated because of signs or symptoms of cervical spinal cord compression. Dexmedetomidine provided adequate sedation. We did not encounter any loss of airway or airway obstruction during the intubation. The patients had excellent cooperation for post-intubation neurologic examination. For those patients who developed transient hypotension after induction of general anesthesia were managed with boluses of phenylephrine or ephedrine. ${ }^{[12]}$

\section{Conclusion}

There was significantly increased percentage of patients with score 2 in study group. ( $82 \%$ vs. $34 \%$ ) where patients were lightly asleep and were easily arousable, responding to commands and they were calm and co-operative. Better conscious score 2(1-3) was more associated with Study group compared to control group 1(1-3).

\section{References}

1. Grant SA, Breslin DS, MacLeod DB, Gleason D, Martin G. Dexmedetomidine infusion for sedation during fiberoptic intubation: a report of three cases. J Clin Anesth. 2004;16(2):124-6.

2. Chu KS, Wang FY, Hsu HT, Lu IC, Wang HM, Tsai CJ. The effectiveness of dexmedetomidine infusion for sedating oral cancer patients undergoing awake Fiberoptic nasal intubation. Eur J Anaesthesiol. 2010;27(1):36-40.

3. Rebecca A. Ruffle DO*, Shaheen Shaikh MD*, Daniel Kim, MD* Awake Fiberoptic Intubation Using Dexmedetomidine in a Compromised Airway Secondary to a Thyroid Carcinoma. June 15, 2010.

4. Abdelmalak B, Makary L, Hoban J, Doyle DJ. Dexmedetomidine as sole sedative for awake intubation in management of the critical airway. J Clin Anesth. 2007;19 (5):370-3.

5. Bergese SD, Khabiri B, Roberts WD, Howie MB, McSweeney TD, Gerhardt MA. Dexmedetomidine for conscious sedation in difficult awake fiberoptic intubation cases.J Clin Anesth. 2007;19 (4):323.

6. Peiris K, Frerk C. Awake intubation.J Perioper Pract. 2008 Mar; 18(3):96-104.

7. Andruszkiewicz P, Dec M, Kański A, Becler R. Awake fibreoptic intubation. Anestezjol Intens Ter. 2010; 42 (4):218-21.

8. Takahashi H, Suzuki T, Onisi T, Senda M, Takada T, Ainoda K, lizuka $\mathrm{H}$, Tagawa K, Onda M. Anesthesia induction for patients with cervical spinal disease . J Neurosurg Anesthesiol. 2005; 17 (2):97-9.

9. Crosby ET. Airway management in adults after cervical spine trauma.Middle East J Anesthesiol. 2011;21(1):99-103).

10. Akhlagh SH, Vaziri MT, Masoumi T, Anbardan SJ. Hemodynamic response to tracheal intubation via direct laryngoscopy and intubating laryngeal mask airway (ILMA) in patients undergoing coronary artery bypass graft (CABG).Middle east J Anesthesiol.2011;21(1):99-103.

11. Shibata Y, Okamoto K, Matsumoto M, Suzuki K, Sadanaga M, Morioka T. Cardiovascular responses to fiberoptic intubation: a comparison of orotracheal and nasotracheal intubation. Anesthesiology. 2002;97(3):592-8.

12. Avitsian R, Lin J, Lotto M, Ebrahim Z. Dexmedetomidine and awake fiberoptic intubation for possible cervical spine myelopathy: a clinical series. Anesthesiology. 2006;104(6):1293-318.

Copyright: () the author(s), publisher. Academia Anesthesiologica International is an Official Publication of "Society for Health Care \& Research Development". It is an open-access article distributed under the terms of the Creative Commons Attribution Non-Commercial License, which permits unrestricted non-commercial use, distribution, and reproduction in any medium, provided the original work is properly cited.

How to cite this article: Babu BDB, Padma S. Clinical Profile of the Patients Undergoing Awake Fiberoptic Intubation Along with Airway Blocks in Cervical Discectomy Patients. Acad. Anesthesiol. Int. 2019;4(2):39-43.

DOI: dx.doi.org/10.21276/aan.2019.4.2.10

Source of Support: Nil, Conflict of Interest: None declared. 